\title{
Impact of Instructional Radio Delivery Mode on Academic Achievement of Distance Learning Students' in Computer Science
}

\author{
Felix Kayode Olakulehin \\ National Open University of Nigeria, Lagos, Nigeria
}

\begin{abstract}
Instructional radio involves the transmission of information, ideas, and opinions through the usage of electronic devices. The open and distance learning (ODL) is becoming more and more relevant and accepted as a form of global education. Radio broadcasting was introduced in Nigeria during the colonial age in 1932. Since then, it has been used for social, political, and mass education. This paper examines the impact of instructional radio delivery mode on academic achievement of distance learning students' in computer science. It was an experimental study conducted on 105 computer science students in Lagos State. Purposive sampling was used to obtain a sample of two study centres in Lagos. The sample was divided into control and experimental groups. One group (control) was taught course contents of computer science with the traditional lecture method and the other group (experimental) was taught using instructional radio. After six weeks of treatment, both groups were given an achievement test. Three instruments were used in the study, and they included achievement test in computer (ATC), entry behaviour text in computer (EBTC), and instructional package in computer - the instruments were developed by the researcher. The instrument was pilot tested to ascertain reliability. Three hypotheses were formulated and tested at 0.05 level of significance. Data were analysed using analysis of convariance (ANCOVA). Findings revealed that: 1. There is no significant effect of treatment (radio instruction and lecture method) on students' performance in computer science $(F=0.363, p>0.05) ; 2$. There was no significant effect of gender on students' achievement in computer science $(F=0.002, p>0.05)$ although males did a bit better than females; and 3 . There is no significant interaction effect of treatment and gender on students' posttest performance in computer science $(F=1.679$, $p>0.05)$. In conclusion, the use of instructional radio combined with lecture method promotes and enhances effective teaching-learning process. Thus, lecturers should be encouraged to use it in university education programme.
\end{abstract}

Keywords: computer science, instructional radio, lecture method, academic achievement and distance learner

\section{Introduction}

The range of technology in education has evolved steadily. It comprises use of computers, radio, multimedia players, and a range of wireless devices that can be used across regions by providing both audio and visual facilities for exchange of instructions. The role of the worldwide Web/Internet has grown

Felix Kayode Olakulehin, research fellow, Regional Training and Research Institute for Open and Distance Learning, National Open University of Nigeria. 
immensely as it helps minimize the costs in reaching millions of students across geographical regions. In the context of Indian education system, Kurrien (2008) stated that the choice of a particular technology - television, radio, computers, or others - must be guided not merely by its availability or wide accessibility, but by the innate characteristics that made it appropriate for the educational goals, curricular objectives, and pedagogical styles, we wanted to promote on a large scale, in keeping with our "National Curricular Framework."

In the 1930s, radio became a popular education technology when the UK Open University first made use of it. The Open University demonstrated that radio had a greater value for weak students who benefit from radio as a supplementary learning tool (Vyas, Sharma, \& Kumar, 2002). The choice of technology tools in education had seen a widening of options, yet radio remains a popular medium in the elementary education system.

In distance learning, the use of high quality radio programs has been found to be successful for expanding access and quality of distance education. Radio is used to teach students who are not in school, who are affected by conflict, who are orphans, who live in countries where most social systems have broken down or never existed - the poorest, least supported, and most remote learners to whom access to education has traditionally been denied and working class. It is also used in systems of huge scale, such as the more than 20 million learners in India (Ho \& Thukral, 2009). The use of radio is found to be very appropriate in such settings where the education system is not very strong, qualified lecturers are scarce, and instructional materials have to be provided on a large scale.

\section{An Overview of Instructional Radio}

Research throws light on the positive aspects of the use of radio technology in education. Various studies around the world show that radio has emerged as an effective tool to bridge gaps in education as it helps in improving the learning outcomes of the students (Anzalone \& Bosch, 2005). Several studies have shown that radio has been used as a tool to reach large audiences in Africa, Latin America, and Pakistan at minimum cost (Ho \& Thukral, 2009). Nations have adopted interactive radio in school education since the 1970s. The popular subjects radio have being used in teaching is mathematics, especially Mental Arithmetic, English, etc.. Radio Math was started in 1974 followed by Kenya (1980), Dominican Republic (1981), Bolivia (1987), Papua New Guinea (1986), Ecuador (1988), and Costa Rica (1989). The South Asian countries first started using radio in 1992 with Pakistan's Radio Math and English in action projects. Bangladesh started in 1994. The Indonesian government started using radio in 1993 for instruction in civics, math, and teacher training. Nepal started using radio for training rural health workers in 1996. India started using radio in school as early as 1937 (Vyas et al., 2002). However, its popularity as a distance learning medium for elementary schools started catching up post 1970s, especially after the 1990s.

Radio has been used extensively as an educational medium in developing countries. Educational radio has been utilized in Thailand, to teach mathematics to school children (Galda, 1990), for teacher training, and other curricula (Akintayo, 1980). India, for rural development (Long, 1984); Swaziland, for public health purposes (Baxter-Magolda, 1999); Mali, for literacy training (Ouane, 1982); Columbia, for various programs (Baxter, 1999); Mexico, for literacy training and other programs (Brookfield, 1986); Nigeria, for management courses for the agriculture sector (Balogun, 1985); Kenya, in support of correspondence courses (Kinyanjui, 1973); Nicaragua, for health education (Cooke \& Romweber, 1977); The Phillipines, for nutrition education (Cooke \& 
Romweber, 1977); Sri Lanka, for family planning and health (Academy for Educational Development, 1980); South Korea, in support of family planning (Park, 1967); Botswana, for civics education (Baxter, 1999); and Paraguay, to offer primary school instruction (Academy for Educational Development, 1979).

In general, the studies done in various countries where radio based instructions have been provided to students in various subjects show a positive result. According to Jamison and McAnany (1978), the educational uses of radio fell into three broad categories: improving educational quality and relevance; lowering educational costs; and improving access to education, particularly in rural areas. An analysis of various radio projects by Jamison and McAnany (1978) across regions showed that radio, if properly used, can teach as well as (or in some cases, better than) traditional instruction. Based on a detailed review of research studies on the uses of radio in education projects in developing countries, Isola (2010) summarized his findings as follows: Evaluation of communication programs, projects, and experiments had repeatedly shown that radio can teach; it can present new concepts and information.

In this regard, they quoted Kinder (1959) who concluded that radio played an effective educational role both as the sole medium and in conjunction with print and group support. Ho and Thukral (2009) found that exposure to interactive radio instruction (IRI) was associated with higher levels of student achievement, consistently producing learning gains among its participants of diverse ages and in diverse settings. In Haiti, Zambia, and Sudan, IRI mathematics instruction has shown positive results with respect to pre-test to post-test gains. Even for early learners, IRI has proved to improve not only increase in access to education, but more importantly, improve student achievement (Radio Instruction to Strengthen Education [RISE] in Tuckman, 1975).

In school education, radio interventions have been used primarily in subjects, like mathematics and English education. There are evidences that suggest that the intervention has helped in improving teaching practices in an unfamiliar subject like a language. Kurrien (2008) brought out the findings of the radio program-We Learn English. It was a bilingual radio program for teaching spoken English in urban and rural schools across various parts of India. The initiative was by the Center for Learning Resources, Pune, in the period of 2000-2008. The program had a substantial impact on large numbers of urban and rural students studying in government schools, helping them start speaking and expressing radio's strengths and its cost effectiveness can be used effectively to meet expanding educational needs in developing countries without a loss in quality of education. India has also experimented with utilizing the innovative tools in bridging the gaps in the education sector. India has not been able to ensure the availability of qualified and well trained teachers across all elementary schools. Hence, techniques like radio for education become an easier option to bridge the gap where qualified teachers are not available or where teachers express difficulty in teaching certain portions of the school curriculum. It has been identified as a way to supplement the regular teaching-learning process in schools.

In the decade of 2000, India adopted radio technology through the IRI intervention to improve the quality of education in elementary schools. It claimed to be a time-tested tool around the world to reach larger audiences in a cost effective manner (European Defence Community [EDC], 2010). From 2000 onwards, IRI was developed and broadcast for elementary schools in various mediums. According to Levy (2003), faculty members were faced with a number of new situations when teaching an online learning class as opposed to a traditional class. These included: the administration or management of online courses; the course layout and design; the best delivery method for the content, such as text, graphics, audio, or video; the various 
communication methods that the students will use, such as e-mail, discussion boards, and chats; ways to increase and maintain student involvement; appropriate student assessments for online learning; and a working knowledge of all the technologies being implemented in the online course (Ely, 2002).

\section{Objectives of the Study}

The objectives of this study include:

1. To determine the effect of instructional radio delivery mode on academic achievement of undergraduate distance learners';

2. To determine gender differences in the use of instructional radio in distance learning;

3. To find out the outcome of using instructional radio in teaching computer science.

\section{Research Hypotheses}

The hypotheses tested in the study are:

1. There is no significant effect of treatment (radio instruction and lecture method) on students' post-test performance in computer science;

2. There is no significant effect of gender on students' post-test performance in computer science;

3. There is no significant interaction effect of treatment and gender on students' post-test performance in computer science.

\section{Literature Review}

Academic performance as a variable in students' learning has been a matter of concern in the present day research. Busari (2009) defined academic performance as the level of achievement in the subject as exhibited by an individual. According to Ogundokun and Adeyemo (2010), academic performance was the exhibition of knowledge attainment or skills developed by students in the school subject usually designed by test scores or by marks assigned by teachers which can be low or high.

Researchers (Lawal, 2007; Usman, 2010; Atadoga \& Lakpini, 2013) found that the persistent low academic achievement was attributed to teacher instructional strategies among others. Thus, instructional strategies used by teachers in teaching-learning process had significant influence on learners' academic achievement. Atadoga and Onaolapo (2008) stated that instructional strategies adopted by teachers at all levels of education in imparting knowledge and skills to the learners were determined by teachers abilities, topic to be taught, learners age, available resources, and available space. Thus, Poopola (2010) ascertained that academic achievement was a function of a various factors, such as method of teaching, teachers' qualifications, child's home background, school environment, attitude, and interest among others.

The concept of gender in teaching and learning process has attracted the attention of many psychologist, biologists, and researchers as a result of which a lot of literatures exist on different aspects of the concepts (Bichi, 2002). Research question No. 2 of this study focuses on academic achievement of male and female students in weather concept. This necessitates the researcher to review some relevant literatures on gender and academic achievement in science education. A considerable amount of researches has focused on gender differences in school learning (Nsofor, 2010). Male show more positive attitudes toward science than females (Prokop, Tuncer \& Chuda, 2007). Moreover, a careful consideration of the statistics of contribution of gender in science. 
Science, technology, engineering, and mathematics (STEM) in Nigeria reveals that the participation of women is significantly low (Olagunji \& Abiona, 2008). Evidences have supported this view in almost every science and technological based organization. Some studies have found gender disparity in the use of instructional methods on students' achievement in favor of male (Bichi, 2002; Usman, 2010; Olagunji \& Abiona, 2008; \& Obeka, 2013). Others have found none (Haruna, 2000, Maikano, 2007, Mari 1994, Usman, 2010). Studies have also revealed that the application of instructional treatment on a mixed gender school population improves the academic performance of students at the same time yield to different responses or results (Smith \& Ragan, 1999).

Olubiyi (2010) in a research on gender disparity on achievement in mathematics of senior secondary school opined that performance of males was higher than that of females. In support of this, Usman (2010) compared the relationship between student's performance and their academic achievement in biology using National Institute of Science and Technology Policy (NISTEP) mode of teaching revealed that senior secondary male biology students performed well in any rigorous work than their female counterpart. In a similar vein, Obeka (2009) conducted a research on epodewalad and power simulation games of geographic and environmental education. The findings of the study, among others, revealed that gender was a significant factor in students' achievement in environmental education concepts of geography with male students' performing better than their female counterparts.

On the contrary, study conducted by Mari (1994) on understanding of science process and its relationship to achievement in integrated science argued that females perform better than males in integrated science. Bichi (2002) worked on effects of gender on historically enriched curriculum on academic achievement in evolution concept using senior secondary biology students. The finding revealed disparity among gender in support of girls.

The findings of Haruna (2000) in his study revealed that there was no significant difference in the performance of gender in chemistry. Maikano (2007) found no significant difference in the academic achievement between male and female students taught ecological concepts the outdoor laboratory instructional strategy. Mari (2010) supported this assertion in his study on entry qualification and performance. The result showed that male and female students admitted with the same entry qualification have no difference in their performance. In addition, Usman (2010) opined that outdoor laboratory method enhanced academic performance of students in spite of their gender.

The causes of disparity between male and female student as observed by Yaga (2002) was the characteristic nature of teachers who were friendlier with boys than girls. Usman (2010) added that it was the ways science was being taught in the classroom that caused the disparity between male and female students. American Psychological Association (APA) (2010) suggested that social and cultural factors perceived or actual performance difference, can also be responsible for this disparity.

\section{Methodology}

\section{Research Design}

The main design employed for this study is the quasi-experimental design for the purpose of evaluating the effects of teaching with instructional radio on academic achievement of undergraduate distance learners' in computer science. The specific study design used in the study is the pre- and post- test control and experimental group design. The statistical method used for the analysis of convariance (ANCOVA) design. The independent 
variables are: gender (male and female), delivery mode for lecture (instructional radio and lecture method), while the dependent variable is academic achievement which is determined either by the gender of the learner or the mode for receiving lectures. The results obtained were linked to the specific hypotheses.

\section{Population and Sample}

The population for this study was made up of the students of National Open Univesity of Nigeria (NOUN) who are studying computer science in the McCarthy and Apapa study centres. Simple random sampling technique was used to select 109 students for the sample from this study. The McCarthy centre was used as the control group while the Apapa centre was used as the experimental group, and 54 students took part in the radio mode delivery and 55 students were used for the lecture method.

\section{Data Collection Procedure}

Data for the study were collected using an evaluation form. A total of 120 evaluation forms were administered to the learners' who were randomly selected among the two study centres used for the study. Every copy of the evaluation form was assessed by the researcher. The learners' were expected to respond to all the questions in the evaluation form. The questions were 20 in number and were presented on a Likert-type scale. Out of the 120 copies of evaluation forms distributed, 104 were found usable. This made up more than $80 \%$ of the evaluation forms. This figure was thus found sufficient for the research to proceed with the data analysis.

\section{Study Instrument}

The instrument involves the script, recorded sound, and the test items.

The script writing involved three stages which are:

1. Developing the outlines: Here, the objectives for the lesson was stated, the main body of the instructional package was also given here and in closing, the students' were told what to look forward to in the next programme;

2. Writing the first draft: The subject specialist was used here to vet the final script that was used in recording in order to guarantee the quality assurance of the production work;

3. Rewriting the script: Here, the finished script is vetted before taken to the studio for the final recording.

For the recorded sound, light music was used for about 10 seconds before the lecture started and there were some music breaks at various intervals for seven seconds to allow the students relax a little and the presenter to catch his breath.

The test items were vetted by a specialist in the field of computer science to ensure the validity of the instrument used.

The instructional radio programme was validated by the head of media in NOUN and four other Ph.D. holders validated the instructional package. In other to ensure that the instructional package was well designed.

\section{Data Analysis}

Descriptive and inferential statistics were used to analyse the data obtained from the study. The descriptive statistics involved the computation of the means and standard deviations from the post-test performance scores of students classified into experimental and control groups, and ability levels. The three hypotheses were tested using the inferential statistics which involved the use of a two-way ANCOVA with the pre-test scores used as 
covariate to the post treatment scores. The post-test scores were used as dependent variables in all the ANCOVA analysis. All the hypotheses were tested at 0.05 level of significance.

\section{Results}

There is no significant effect of treatment (radio instruction and lecture method) on students' performance in computer science.

To test hypothesis 1 , Table 1 is presented.

Table 1

ANCOVA Table for Post-Test Performance Scores of Students by Treatment and Gender

\begin{tabular}{|c|c|c|c|c|c|c|}
\hline Source & Source & $\begin{array}{l}\text { Type III sum } \\
\text { of squares }\end{array}$ & $d f$ & Mean square & $F$ & Sig. $(p)$ \\
\hline \multirow{2}{*}{ Intercept } & Hypothesis & 2802.019 & 1 & 2802.019 & \multirow{2}{*}{43.262} & \multirow{2}{*}{0.000} \\
\hline & Error & 6736.935 & 104.014 & 64.769 & & \\
\hline \multirow{2}{*}{ Pre-test } & Hypothesis & 3227.899 & 1 & 3227.899 & \multirow{2}{*}{48.813} & \multirow{2}{*}{0.000} \\
\hline & Error & 6877.340 & 104 & 66.128 & & \\
\hline \multirow{2}{*}{ Group } & Hypothesis & 40.491 & 1 & 40.491 & \multirow{2}{*}{0.363} & \multirow{2}{*}{0.655} \\
\hline & Error & 110.352 & 0.991 & 111.406 & & \\
\hline Gender & Hypothesis & 0.218 & 1 & 0.218 & 0.002 & 0.971 \\
\hline \multirow{3}{*}{ Group gender } & \multirow{3}{*}{$\begin{array}{l}\text { Error } \\
\text { Hypothesis }\end{array}$} & 114.604 & 1.048 & 109.311 & \multirow{3}{*}{1.679} & \multirow{3}{*}{0.198} \\
\hline & & 111.046 & 1 & 111.046 & & \\
\hline & & 6877.340 & 104 & 66.128 & & \\
\hline
\end{tabular}

From Table 1, the effect of treatment on students' performance in computer science is not significant $(F=$ $0.363, p>0.05$ ). This means that students taught using radio instruction and those taught using the lecture method are not significantly different in their posttest scores. Hypothesis 1 is therefore, not rejected.

In order to find out the magnitude of the mean scores for the experimental and control groups. Table 2 is presented.

Table 2

Estimated Marginal Means for Experimental and Control Groups at Post-Test

\begin{tabular}{lllll}
\hline \multirow{2}{*}{ Group } & \multirow{2}{*}{ Mean } & Std. error & \multicolumn{2}{c}{$95 \%$ confidence interval } \\
\cline { 4 - 5 } & & 1.111 & Lower bound & Upper bound \\
\hline Experimental group & 80.144 & 1.231 & 77.942 & 82.346 \\
Control group & 78.846 & 76.405 & 81.288 \\
\hline
\end{tabular}

The performance (mean score) of the experimental group is 80.144 while the experimental mean score of the control group is 78.846 . The difference between the two mean scores is 1.298 with the experimental group scoring higher.

Hypothesis 2: There is no significant effect of gender on students' posttest performance in computer science.

To test hypothesis 2, Table 2 on ANCOVA is used.

From Table 2, it shows that the effect of gender on students' performance in computer science at post-test is not significant $(F=0.002, p>0.05)$. This means that males and females are not significantly different in their post-test performance scores. Hypothesis 2 is therefore, not rejected.

In order to find out the magnitude of male and female students, Table 3 is presented. 
The post-test (mean score) of males is 79.446 while the post-test mean score of the females is 79.544 . The difference between the two mean score is 0.098 with the female scoring higher which implied that they performed better than the females.

Table 3

Estimated Marginal Means for Male and Female Students at Post-Test

\begin{tabular}{lllll}
\hline \multirow{2}{*}{ Gender } & Mean & Std. error & \multicolumn{2}{c}{ 95\% confidence interval } \\
\cline { 4 - 5 } & & & Lower bound & Upper bound \\
\hline Male & 79.446 & 1.050 & 77.363 & 81.529 \\
Female & 79.544 & 1.308 & 76.949 & 82.138 \\
\hline
\end{tabular}

Hypothesis 3: There is no significant interaction effect of treatment and gender on students' posttest performance in computer science.

To test hypothesis 3, Table 3 on ANCOVA is used.

From Table 3, the effect of treatment and gender on students' performance in computer science at posttest is not significant $(F=1.679, p>0.05)$. This means that male and the female students are not significantly different in their posttest performance scores. Hypothesis 3 is therefore, not rejected.

In order to determine the nature of interaction of treatment and gender, Table 4 is presented.

Table 4

Estimated Marginal Means for Interaction Effect of Treatment and Gender on Posttest Scores

\begin{tabular}{llllll}
\hline \multirow{2}{*}{ Group } & \multirow{2}{*}{ Gender } & \multirow{2}{*}{ Mean } & Std. error & \multicolumn{2}{c}{ 95\% confidence interval } \\
\cline { 5 - 6 } Experimental & Male & 81.174 & 1.641 & 77.919 & Upper bound \\
group & Female & 79.114 & 1.541 & 76.058 & 84.429 \\
\multirow{2}{*}{ Control group } & Male & 77.719 & 1.291 & 75.158 & 82.170 \\
& Female & 79.974 & 2.102 & 75.806 & 80.279 \\
\hline
\end{tabular}

The mean score for the males in the experimental group is 81.174 while the mean score for the females in that group is 79.114. However, in the control group, the mean scores of the males are 77.719 while the females are 79.974. This means that the interaction is disordinal, because the males in the experimental group had a higher mean score while the females in the control group had higher mean scores.

\section{Discussion}

The findings from this study revealed that there was no significant effect of treatment on students' academic achievement in computer science. The researcher found out that the students' who were taught with instructional radio achieved slightly higher scores in the Computer Adaptive Test (CAT), test scores compared to the students taught using the lecture method. It is therefore observed that using instructional radio assists the students', thereby, making the students to use their intellectual ability in the teaching and learning process.

This study also revealed no significant effect of gender on students' academic achievement in computer science. This implies that both male and female students achieved equally under the same condition during learning and teaching process, since academic achievement has to do with mental and intellectual ability and not gender. This result agreed to the view of Moronfola (2002) who stressed that science subjects should be taught primarily as a practical subject. Olumorin (2006) ascertained that in modern science curriculum 
programme, students (male and female) needed to be encouraged not to learn only through their eyes but their ears also and should be able to use their hands to manipulate objects.

This study also discovered that no significant interaction effect of treatment and gender on students' post test performance, this result agreed with the view of Moldstad (1974) study on gender difference in secondary school mathematics which stated that there was no significant difference between male and female students in the study of mathematics.

\section{Conclusion}

Based on the findings of the study, the followings were derived. There is no significant effect of treatment on students' post-test performance in computer science in NOUN. This study also shows that effect of gender on students' post-test performance in computer science is not significant. The effect of treatment and gender on students' post-test performance in computer science is not significant.

There is need for instructional radio to be used in teaching which can also be used to supplement, clarify, vitalize, emphasize, instruct, and enhance learning in the process of transmitting knowledge, ideas, skills, and attitude. The ability of the lecturers' to make use of instructional radio improves students' academic achievement.

\section{Recommendations}

Based on the findings and conclusions of this study, the following recommendations were made:

1. The use of radio broadcast should be improved on in open and distance learning in other to improve learning efficiency;

2. Radio broadcast should also be encouraged in open and distance learning so that more students who are working can also be listening to the radio programme at the same time without their job been disrupted;

3. More students should be encouraged to accept the use of radio broadcast as a means of learning.

\section{References}

Akintayo, A. (1980). A survey of the learning and teaching problems of history in secondary schools in ekiti central local government. Nigeria: Ondo.

Atadoga, M. M., \& Lakpini, M. A. (2013). A comparison of numeracy achievement of primary school pupils taught using whole class and varied classroom organization instructions. Proceedings of Multicultural African Conference. Zaria: Ahmadu Bello University.

Atadoga, M. M., \& Onaolapo, M. A. O. (2008). A handbook on science teaching method. Zaria: Shola Press.

Balogun, T. A. (1985). Interest in science technology education in Nigeria. Journal of Teachers Association of Nigeria, 23(1 \& 2), 92-99.

Baxter, M. M. (1999). Creating contexts for learning and self-authorship. Nashville, T.N.: Vanderbilt University Press.

Bichi, S. (2002). Effects of problem solving strategy and enriched curriculum on students' achievement in evolution concepts among secondary school students (Unpublished doctoral dissertation, Faculty of education, Ahmadu Bello University, Zaria).

Brookfield, S. (1986). Media power and the development of media literacy: An adult educational interpretation. Harvard Educational Review, 56(2), 151-171.

Busari, A. T. (2009). Field study in geography, an inevitable tool for acquiring observatory and analytical skills. Informational Journal of Research in Education, 6(1 \& 2).

Cook, T. D., \& Curtin, T. R. (1985). Evaluating the CTW model for producing educational television. Journal of Educational Communication and Technology, 33(2), 91-112.

Cooke, T., \& Romweber, G. (1977). Radio nutrition education-Using the advertising techniques to reach rural families: Philippines and Nicaragua. Washington, D.C.: Manoff International. 
Ely, D. (2002). Trends in educational technology (5th ed.). Syracuse, N.Y.: ERIC Clearinghouse on Information \& Technology.

Galda, L. (1984). The relations between reading and writing in young children. New Directions in Composition Research, 191-204.

Galda, K., Beach, K., Friend, J., \& Gamero, G. (1990). The impact of Honduras mental arithmetic radio programs on student achievement in Grades 1 and 2. Newton, M.A.: Education Development Center, Radio Learning Project.

Ho, J., \& Thukral, H. (2009). Tuned in to student success: Assessing the impact of interactive radio instruction for the hardest-to-reach. Journal of Education for International Development, 4(2), 34-51.

Isola, O. M. (2010). Effects of standardized and improvised instructional materials on students' academic achievements in seconadry school physics (M. Ed. thesis, University of Ibadan, Ibadan).

Jamison, D. T., \& McAnany, E. G. (1978). Radio for education and development. New York, N.Y.: Sage Publications.

Kinder, J. S. (1959). Audio visual materials and techniques (2nd ed.). New York: American Book Company.

Kinyanjui, P. E. (1973). Radio/correspondence courses in Kenya: An evaluation. Educational Broadcasting International, 6(4), 180-187.

Kurrien, Z. (2008). The use of educational radio for improving the quality of teaching and learning in government regional medium elementary schools. In Consultation on National Policy on ICTs in School Education. Niger: Abuja.

Lawal, T. E. (2007). Think and do activity and its effect on the performance of pupils in primary science in selected primary schools in Zaria Municipality, Nigeria. Journal of Science and Mathematics Education, 3(1), 87-92

Levy, S. (2003). Six factors to consider when planning online distance learning programs in higher education. Online Journal of Distance Learning Administration, 6(1).

Maikano, S. (2007). Effects of outdoor and indoor laboratory experience on secondary school students' academic achievement and retention in ecology in Kaduna State (Unpublished M. Ed. thesis, Department of Education, Ahmadu Bello University, Zaria).

Mari, J. S. (2010). The understanding of science processes and its relationship to achievement in integrated science (M.Ed. thesis. Department of Education, Ahmadu Bello University, Zaria).

Moldstad, J. A. (1974). Selective review of studies showing media effectiveness. A primer for Media Directors AVCR, 22(1), 387-407

Moronfola, B. (2002). Effects of instruction resources on the academic achievements of secondary school students in Ilorin Local Government of Kwara State (Unpublished M.Ed. research thesis, University of Ilorin, Nigeria).

Nsofor, C. C. (2010). Effects of improvised instructional media on Niger state secondary school students' achievement in selected biology concepts (Unpublished Ph.D. dissertation, Federal university technology, Minna).

Obeka, S. S. (2009). Epodewalad and power simulation games of geographical and environmental education. Zaria: Ahmadu Bello University Press Limited, 120

Obeka, A. (2013). Effects of innovative teaching strategies with integrated resource materials on academic achievement for access and quality environmental education in otukpo educational Zone, Benue State, Nigeria. Proceedings of Multicultural African Conference, Zaria, Ahmadu Bello University.

Ogundokun, M. O., \& Adeyemo, D. A. (2010). Emotional intelligence and academic achievement: The moderating influence of age, intrinsic, and extrinsic motivation. The African Symposium, 10(2), 127-141.

Olagunji, A. M., \& Abiona, O. F. (2008). Production and utilization of resources in biology education: A case study of South-West Nigerian secondary schools. International Journal of African and American Studies, 7(2), 49-57. Retrieved 2 November, 2016, from http://Ojcs,siue.edu/Ojs/index.php/ijaaas/article/viewFile/113/177

Olubiyi, A. (2000). Understanding educational technology. Lagos: Evasan Limited.

Olumorin, C. O. (2006). An assessment of government controlled educational media broadcast in Nigeria, lecture monograph. Ilorin: Department of Science Education.

Park, R. E. (1967). On social control and collective behavior. Chicago: University of Chicago Press.

Prokop, P., Tuncer, G., \& Chuda, J. (2007). Slovakian students' attitudes toward biology. Eurasia Journal of Mathematics, Science and Technology Education, 3(4), 287-295.

Poopola, A. (2010). Teacher's mathematics anxiety as a correlate of pupil's attitude to mathematics. Research in Curriculum Studies (RICS), 3(2).

Smith, P., \& Ragan, T. (1999). Instructional design (2nd ed.). Merril, N.J.: Upper Saddle River.

Thukral, J. H., \& Jennifer, H. (2009). Tuned in to student success: Assessing the impact of interactive radio iinstruction for the hardest to reach. European Defence Community (EDC). 
Tuckman, B. W. (1975). Measuring educational outcomes. New York, N.Y.: Harcourt Brace Hovawick Inc..

Usman, I. A. (2010). The effects of indoor and outdoor instructional methods on academic achievement of JSS integrated science students in Zaria local government area, Kaduna State. Journal of Science and Mathematics Education, 1(1). 66-73, 124

Vyas, R. V., Sharma, R. C., \& Ashwini, K. (2002). Educational radio in India. Turkish Online Journal of Distance Education-TOJDE, 3(3).

Yaga, R. E. (2002). Science teacher society as a reform. School Science and Mathematics, 93(3), 145-158. 